Focused on "Showcasing Structural Integrity Research in India"

\title{
Interfacial shear strength of carbon nanotubes based hybrid composites: effect of loading rate
}

\author{
Harpreet Singh Bedi, Beant Kaur Billing, Prabhat K. Agnihotri \\ Mechanics of Advanced Materials Laboratory, Department of Mechanical Engineering, Indian Institute of Technology Ropar, \\ Punjab, India \\ harpreet.bedi@iitrpr.ac.in, https://orcid.org/0000-0001-5662-0071 \\ beant.kaun@iitrpr.ac.in \\ prabhat@iitrpr.ac.in, bttps:/ / orcid.org/0000-0002-8332-9279
}

\begin{abstract}
Interfacial interaction is investigated between the two basic constituents in Carbon Fiber Reinforced Plastics (CFRPs). Efforts have been made to quantify the Interfacial Shear Strength (IFSS) between individual Carbon Fiber (CF) and epoxy matrix in CFRPs by performing single fiber micro-droplet debond test. Initially, IFSS of the epoxy composites reinforced with unsized or Heated Carbon Fiber (HCF) is assessed. Study is then extended to assess the IFSS of Carbon Nanotubes (CNTs) based CFRP hybrid composites. The hybrid composites are prepared by reinforcing epoxy matrix with CNT grafted Carbon Fibers (CNTCF). The versatile, simple and time effective method of chemical vapor deposition is used to synthesize CNTs directly on the surface of CF. IFSS is found to enhance after the inclusion of grafted CNTs in CFRP composites. Keeping in mind the application view point of CFRPs to put up with varying loads, effect of loading rate on the IFSS of CFRPs is also examined. To this end, both $\mathrm{HCF} /$ epoxy and CNTCF/epoxy composites are debonded at cross-head rates varying by two orders of magnitude and IFSS values are compared. Finally, scanning electron microscopy of debonded fibers is carried out to understand the interfacial failure mechanism in various composites.
\end{abstract}

KEYwORDS. Carbon Fiber; CFRP; CNTs; Epoxy; IFSS; Microbond.

\section{open Access}

Citation: Bedi, H.S., Billing, B.K.., Agnihotri, P.K., Interfacial shear strength of carbon nanotubes based hybrid composites: effect of loading rate, Frattura ed Integrità Strutturale, 48 (2019) $571-576$

Received: 17.11 .2018

Accepted: 16.02 .2019

Published: 01.04.2019

Copyright: (C) 2019 This is an open access article under the terms of the CC-BY 4.0 , which permits unrestricted use, distribution, and reproduction in any medium, provided the original author and source are credited.

\section{INTRODUCTION}

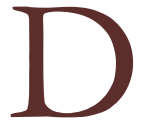
ue to increasing popularity and demand, Carbon Fiber Reinforced Plastics (CFRPs) are finding their way in applications that are likely to comprise high strain rate loading [1]. So, it becomes a necessity for CFRPs to be able to bear the complex environmental and loading conditions and their properties must not deteriorate at varying strain rates. Thus, to serve better the ever widening scope of engineering applications, it is vital for the composite materials to retain their mechanical performance at both quasi-static and/or dynamic loading conditions. This is 
imperative for CFRPs so as to avoid any chances of premature and unexpected failure [1]. In order to sustain the structural integrity of a composite member at varying load conditions, the fiber/matrix bond strength is an important parameter which if optimized improves the mechanical performance of the composite [2]. The average mechanical properties of CFRP laminated composites largely depend on the direct interaction and extent of bonding between the individual reinforcing fiber and the surrounding matrix [3]. Stronger the interfacial interaction better the composite properties. Interfacial bond strength can be tailored in many ways such as by texturing the fiber surface [4], modifying the matrix [5], functionalization of fiber surface, type of fiber, modification of fiber sizing [2] etc. The exceptional properties of Carbon Nanotubes (CNTs) [6] have made them a superior candidate in improving the mechanical properties of CFRPs. The potential of CNTs is harnessed in CFRPs in two ways: by preparing polymer nanocomposites [7] by dispersing CNTs in polymer matrix and by growing CNTs directly on the surface of Carbon Fiber (CF) [8]. In both the cases, bonding between fiber and matrix is affected by the presence of CNTs [3] at the interface.

Interfacial strength primarily depends on the area of contact available on the fiber surface to interact with the matrix [9] which can be increased by synthesizing CNTs on the surface of fiber [10,11]. Additionally, grafted nanotubes improve the wettability of fiber with matrix by increasing the surface energy of unsized carbon fiber [10] ultimately enhancing the ability of the fiber to attract the matrix [14] and spread it more efficiently. This leads to an improvement in stress transfer between fiber and matrix through an enhanced interfacial area, mechanical interlocking and localized stiffening of the matrix [8]. A direct measure of the interfacial bond strength can be estimated from Interfacial Shear Strength (IFSS) at the fiber/matrix interface with the help of single fiber micro-droplet debond test or simply microbond test [12].

Accordingly, debond tests are performed on epoxy matrix composites reinforced with single unsized/Heated Carbon Fiber (HCF) and CNT grafted Carbon Fiber (CNTCF) and hence IFSS is evaluated from the load-displacement data so obtained. Furthermore, the effect of load rate variation on the IFSS of both the composites is also evaluated. Scanning electron micrographs of debonded HCF and CNTCF help us to better understand interfacial failure mechanism in unsized and hybrid composites.

\section{EXPERIMENTAL}

\section{Preparation of CNT grafted carbon fiber}

7 he as-received carbon fabric (Hindoostan Technical Fabrics, India) is firstly heated at $450^{\circ} \mathrm{C}$ to make it free from the sizing layer applied on it. A bunch of heat treated sizing free or unsized carbon fibers (HCF) is then separated from the heated fabric and is coated with nickel catalyst for synthesizing CNTs on fiber surface using dip coating method. The details of preparation of catalyst solution and the dip coating process are described in Ref. [13]. Once the unsized fibers are coated with catalyst, they are subjected to the reactive environment of argon, hydrogen and acetylene gases inside a Chemical Vapour Deposition (CVD) reaction chamber (Technos Instruments, India) as per the procedure detailed in Ref. [14]. After the successful completion of a CVD cycle, the catalyst coated CFs gets transformed into CNT coated CFs. Surface morphology of as-received (ar-CF), unsized (HCF) and CNT grafted carbon fiber (CNTCF) can be seen in Fig. 1. Where, as-received fibers appear smooth (Fig. 1a) because of the sizing layer on their surface, the rough surface of unsized fiber helps in retaining the catalyst particles in a better way (Fig. 1b). It is clear from Fig. 1c that the synthesized CNTs uniformly cover the fiber surface. Composites are then prepared with both unsized and CNT grafted CF using epoxy as matrix as described in the next section.
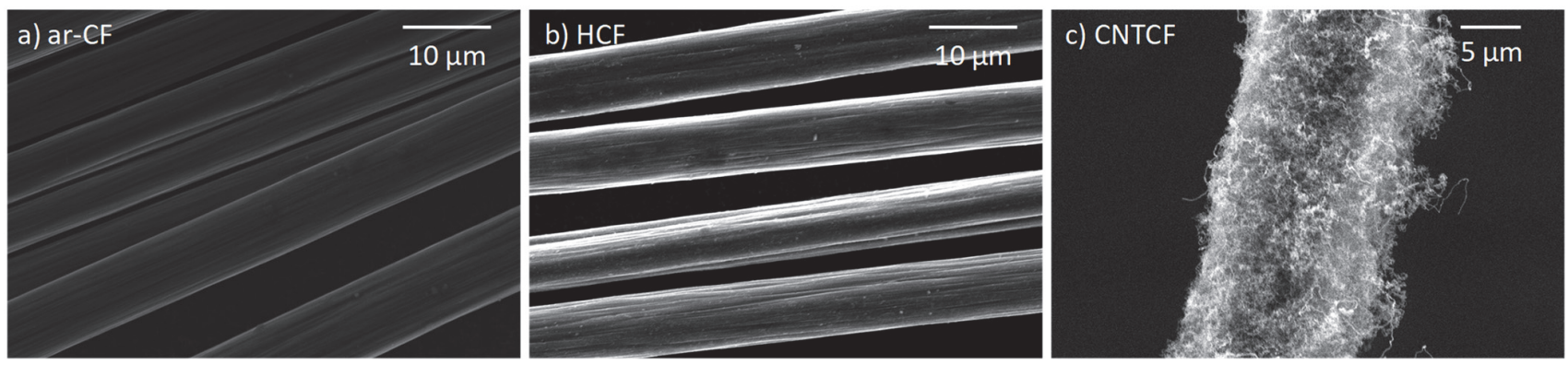

Figure 1: SEM micrograph of: (a) as-received, (b) unsized and (c) CNT grafted carbon fiber. 


\section{Interfacial characterization}

In order to evaluate the shear strength of the fiber/matrix interface, micro-droplet debond tests are carried out with both $\mathrm{HCF} /$ epoxy as well as CNTCF/epoxy composites. Schematic of sample preparation is shown in Fig. 2a where the ends of a single CF filament (unsized or CNT grafted) are first attached to a channel section stand with the help of a quick setting adhesive. Epoxy matrix is prepared by mixing epoxy besphenol resin with polyamine hardener in a ratio of 1:2 by weight. As soon as a drop of matrix is poured on a fiber it disintegrates into multiple micro-droplets as shown in Fig. 2a.

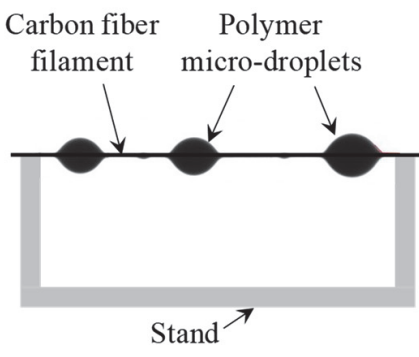

(a)

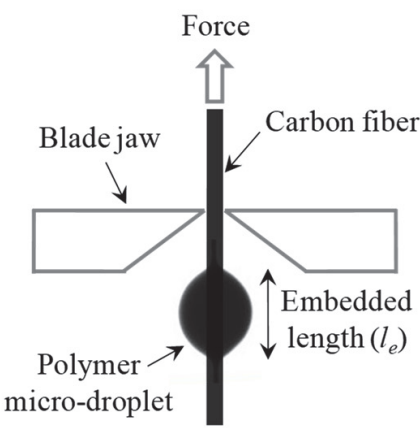

(b)

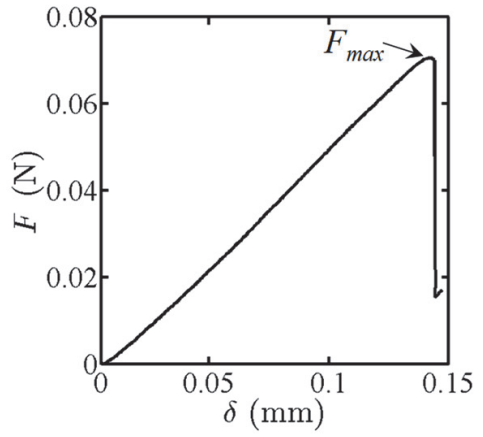

(c)

Figure 2: Schematic of single fiber micro-droplet debond test: (a) polymer micro-droplets adhering the surface of single carbon fiber filament. (b) Test specimen undergoing debond test. (c) Representative load $(F)$ vs. displacement $(\delta)$ curve for the debond test.

Afterwards, the specimens are allowed to cure at atmospheric conditions for at least $24 \mathrm{hr}$ followed by post curing in an electric oven at $60^{\circ} \mathrm{C}$ for $4 \mathrm{hr}$. During this period of curing, matrix droplets set and get hard, adhering the fiber surface to the best of their potential. Debond test is then performed on a universal testing machine (Shimadzu, Japan) as illustrated in Fig. 2b. Crosshead speed is varied from 0.05 to $5 \mathrm{~mm} / \mathrm{min}$ and load $(F)$ vs. displacement $(\delta)$ data is logged corresponding to each speed and for each sample. A typical load/displacement curve obtained from such a test is shown in Fig. 2c. Peak force $\left(F_{\max }\right)$ required to debond a micro-droplet from the fiber is obtained from these curves and interfacial shear strength (IFSS) is then evaluated using Eqn. (1).

$$
I F S S=\frac{F_{\max }}{\pi d l_{e}}
$$

where, $d$ is the fiber diameter and $l_{e}$ is the embedded length of a polymer micro-droplet on the carbon fiber (see Fig. 2b for detail). The small rise after the abrupt drop in load $(F)$ corresponds to frictional sliding effects.

\section{RESULTS AND DISCUSSION}

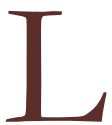

oad or stress transfer from matrix to fiber in CFRPs critically depends on the strength of the fiber/matrix interface. Single fiber micro-droplet debond test is a simple way to measure the interfacial shear strength (IFSS) in CFRP composites. Figs. $3 \mathrm{a}$ and $3 \mathrm{~b}$ show the variation of maximum debond force $F_{\max }$ as a function of varying embedded length $l_{e}$ of polymer micro-droplet for each fiber/matrix composite. The results of debond test are fitted well with linear interpolation, indicating the direct proportionality between peak load and embedded length of the microdroplet. Therefore, IFSS of each composite is evaluated from the slope of a linear fit to the experimental data (markers in Figs. 3a and 3b) and average IFSS with standard deviation is shown in Fig. 3c.

On increasing the loading speed from 0.05 to $5 \mathrm{~mm} / \mathrm{min}$ the IFSS of HCF/epoxy composite rises from $50 \mathrm{MPa}$ to 54 $\mathrm{MPa}$ (Figs. 3a and 3c) by $8 \%$. Similarly, the IFSS of CNTCF/epoxy composite increases by $6 \%$ from $66 \mathrm{MPa}$ (at 0.05 $\mathrm{mm} / \mathrm{min}$ ) to $70 \mathrm{MPa}$ (at $5 \mathrm{~mm} / \mathrm{min}$ ) (see Figs. 3b and 3c). It is observed from Figs. 3a and 3b that at higher speed of loading the slope of the linear fit is higher than the one obtained at lower speed. This corresponds to an increase in IFSS with loading speed irrespective of the type of fiber (HCF or CNTCF) used to reinforce epoxy. This could be attributed to increased yielding of the matrix due to strain hardening effects at higher load speeds, resulting in more energy required to fracture [15]. The energy to fail the composite is determined from area under the load-displacement curve (Fig. 2c) which shows an increasing trend when the rate of loading is increased and/or CNTs are grafted on fiber surface. 
However, at a particular loading rate, composites reinforced with CNT grafted carbon fiber show enhanced IFSS than the ones having just unsized fiber (Fig. 3c). Compared to HCF/epoxy composites, increments of 32\% and 30\% are observed for IFSS of CNTCF/epoxy composites at 0.05 and $5 \mathrm{~mm} / \mathrm{min}$ crosshead speeds, respectively. Moreover, the elastic interaction between the reinforcing fiber and matrix governs the strain rate dependence [1]. Thus, changes in IFSS are expected when the fiber/matrix interfacial interaction is modified by incorporating grafted CNTs in the composite system. One of the reasons behind this observation is the increase in fiber surface area [16] due to CNT grafting, which improves the wettability of CNT grafted carbon fiber with epoxy matrix [17] and hence the mechanical properties of the hybrid composite [14]. Therefore, CNT grafting proves to be effective in improving the shear strength of CFRPs at all loading rates considered in this study and facilitates their usage under situations of low and/or high strain rates. One more advantage of using grafted carbon nanotubes is the resistance that they offer to brittle failure in CFRP composites. The outwardly projecting grafted CNTs mechanically interlock with the surrounding matrix and offer frictional sliding after fiber gets debonded from the matrix [13], consequently preventing catastrophic failure either by avoiding or delaying the crack propagation.
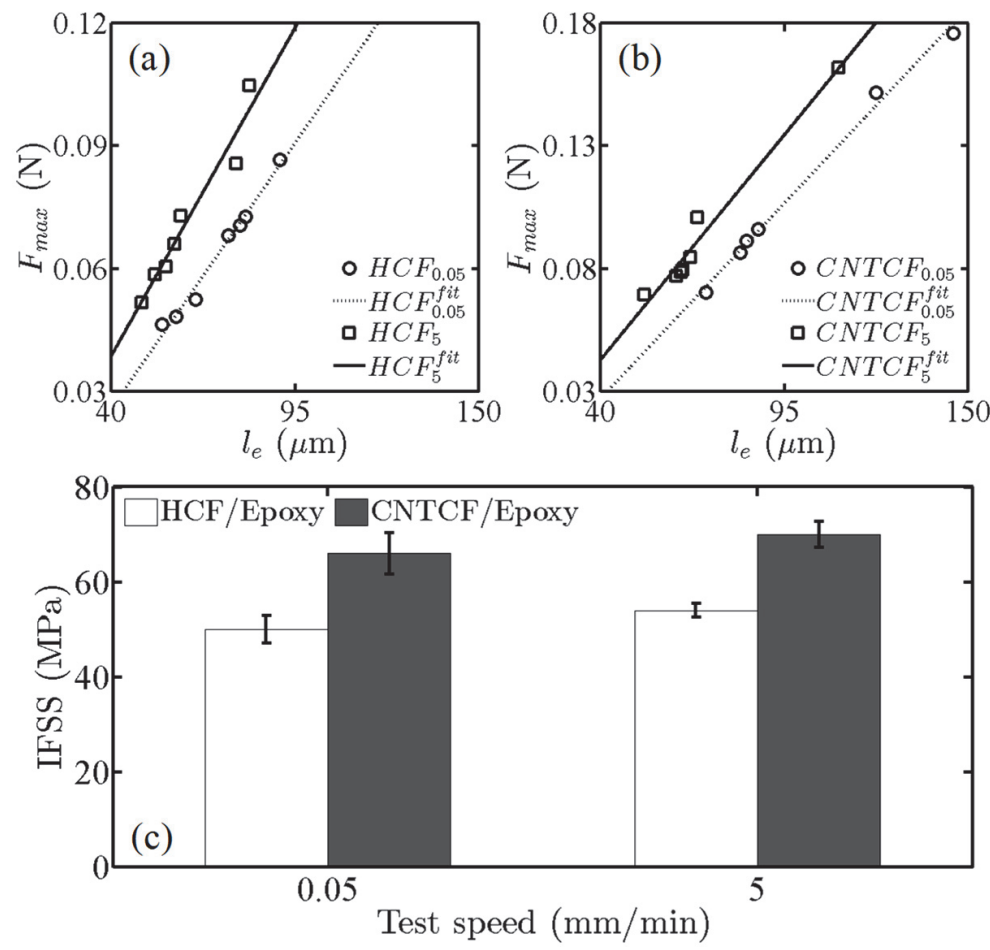

Figure 3: Maximum debond force $\left(F_{\max }\right)$ versus embedded length $\left(l_{e}\right)$ for epoxy composite reinforced with: (a) unsized carbon fiber (HCF) and (b) CNT grafted carbon fiber (CNTCF). (c) Interfacial shear strength (IFSS) of various composites at different load speeds.
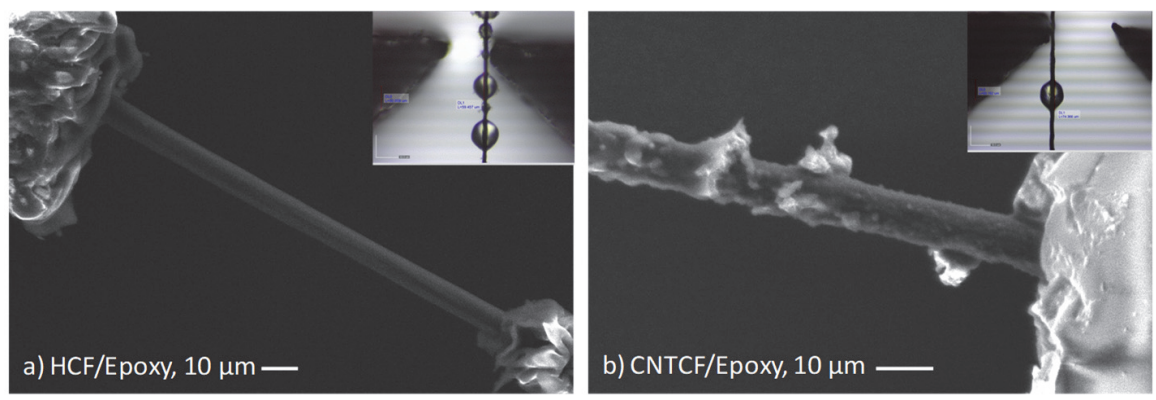

Figure 4: SEM micrographs of single fiber filament after debond test: (a) unsized and (b) CNT grafted carbon fiber debonded from epoxy droplet. Inset shows the optical image (Dino-Lite, Taiwan) of drop on fiber before testing.

In order to get some idea about the observed differences in IFSS of CFRPs reinforced with or without CNTs, SEM 
analysis is performed on the failed fiber surfaces. Fig. 4 presents the analysis of the surface of debonded fibers using SEM, throwing some more light on the failure mechanism of different fiber/epoxy composites. The presence of matrix debris adhering the surface of CNT grafted CF debonded from epoxy (Fig. 4b) implies that failure occurs at the interface of nanotubes and matrix away from the CF/epoxy interface [13]. Whereas, the clean surface of debonded fiber in HCF/epoxy composites (Fig. 4a) suggests failure taking place at the fiber/epoxy interface. This implies poor interfacial bond in HCF/epoxy composites and lower IFSS as compared to CNTCF/epoxy composites.

\section{CONCLUSION}

he effect of loading rate and grafted CNTs on the interfacial shear strength (IFSS) of carbon fiber reinforced epoxy composites is studied. Single fiber micro-droplet debond tests are carried out on unsized and CNT grafted carbon fiber epoxy composites at two displacement rates of 0.05 and $5 \mathrm{~mm} / \mathrm{min}$. An increase in IFSS is observed by increasing the test speed for both unsized and CNT grafted carbon fiber reinforced epoxy composites. The benefit of incorporating grafted CNTs in the composite system is clear from the high values of IFSS for CNTCF/epoxy composites than HCF/epoxy composites. IFSS of CNT based hybrid composites are approximately $30 \%$ higher than their non-CNT counterparts. At higher speeds of loading, matrix is found to play a more significant role in the failure process by yielding more to increase the energy of fracture and hence the IFSS of the composite.

\section{ACKNOWLEDGEMENT}

A uthors would like to thank the financial support and lab facilities provided by Indian Institute of Technology Ropar to carry out this research work.

\section{REFERENCES}

[1] Jacob, G.C., Starbuck, J.M., Fellers, J.F., Simunovic, S. and Boeman, R.G. (2004). Strain rate effects on the mechanical properties of polymer composite materials, J. Appl. Polym. Sci., 94(1), pp. 296-301.

[2] Sockalingam, S. and Nilakantan, G. (2012). Fiber-matrix interface characterization through the microbond test, International Journal of Aeronautical and Space Sciences, 13(3), pp. 282-295.

[3] Qian, H., Bismarck, A., Greenhalgh, E.S., Kalinka, G. and Shaffer, M.S. (2008). Hierarchical composites reinforced with carbon nanotube grafted fibers: the potential assessed at the single fiber level, Chem. Mater., 20(5), pp. 18621869.

[4] Gao, X., Jensen, R., Li, W., Deitzel, J., McKnight, S. and Gillespie Jr, J. (2008). Effect of fiber surface texture created from silane blends on the strength and energy absorption of the glass fiber/epoxy interphase, Journal of Composite Materials, 42(5), pp. 513-534.

[5] Chandrasekaran, V., Advani, S. and Santare, M. (2011). Influence of resin properties on interlaminar shear strength of glass/epoxy/MWNT hybrid composites, Composites, Part A, 42(8), pp. 1007-1016.

[6] Breuer, O. and Sundararaj, U. (2004). Big returns from small fibers: a review of polymer/carbon nanotube composites, Polym. Compos., 25(6), pp. 630-645.

[7] Winey, K.I. and Vaia, R.A. (2007). Polymer nanocomposites, MRS Bull., 32(04), pp. 314-322.

[8] Qian, H., Greenhalgh, E.S., Shaffer, M.S. and Bismarck, A. (2010). Carbon nanotube-based hierarchical composites: a review, J. Mater. Chem., 20(23), pp. 4751-4762.

[9] Li, M., Gu, Y.Z., Liu, Y.N., Li, Y.X. and Zhang, Z.G. (2013). Interfacial improvement of carbon fiber/epoxy composites using a simple process for depositing commercially functionalized carbon nanotubes on the fibers, Carbon, 52, pp. 109-121.

[10] Li, Q., Church, J.S., Naebe, M. and Fox, B.L. (2016). Interfacial characterization and reinforcing mechanism of novel carbon nanotube-Carbon fibre hybrid composites, Carbon, 109, pp. 74-86.

[11]Jiang, D., Liu, L., Long, J., Xing, L., Huang, Y., Wu, Z., Yan, X. and Guo, Z. (2014). Reinforced unsaturated polyester composites by chemically grafting amino-POSS onto carbon fibers with active double spiral structural spiralphosphodicholor, Compos. Sci. Technol., 100, pp. 158-165. 
[12] An, F., Lu, C., Guo, J., He, S., Lu, H. and Yang, Y. (2011). Preparation of vertically aligned carbon nanotube arrays grown onto carbon fiber fabric and evaluating its wettability on effect of composite, Appl. Surf. Sci., 258(3), pp. 1069-1076.

[13] Agnihotri, P., Basu, S. and Kar, K. (2011). Effect of carbon nanotube length and density on the properties of carbon nanotube-coated carbon fiber/polyester composites, Carbon, 49(9), pp. 3098-3106.

[14] Bedi, H.S., Padhee, S.S. and Agnihotri, P.K. (2018). Effect of carbon nanotube grafting on the wettability and average mechanical properties of carbon fiber/polymer multiscale composites, Polym. Compos., 39(S2), pp. E1184-E1195.

[15] Okoli, O.I. (2001). The effects of strain rate and failure modes on the failure energy of fibre reinforced composites, Composite Structures, 54(2-3), pp. 299-303.

[16] Bedi, H.S., Tiwari, M. and Agnihotri, P.K. (2018). Quantitative determination of size and properties of interphase in carbon nanotube based multiscale composites, Carbon, 132, pp. 181-190.

[17] Bedi, H.S., Padhee, S.S. and Agnihotri, P.K., editors. On the nature of interface of carbon nanotube coated carbon fibers with different polymers. IOP Conference Series: Materials Science and Engineering; 2016: IOP Publishing; 2016. 